\title{
Effect of redispersible polymer powder on setting time of thin-bed mortars
}

\author{
Marcin Kulesza ${ }^{1, *}$, Dawid Dębski ${ }^{1}$, and Jadwiga Fangrat $^{2}$ \\ ${ }^{1}$ Atlas sp. z o. o., Kilińskiego 2, Łódź, 91-421, Poland \\ ${ }^{2}$ Instytut Techniki Budowlanej, Filtrowa 1, Warszawa, 00-611, Poland
}

\begin{abstract}
The aim of work is to describe and to complement the existing knowledge on the effect of redispersible polymer powder on the setting time of cement mortar as measured by means of ultrasonic apparatus. The mortars were simple mixtures of filler in the form of quartz sand, Portland cement CEM I 42.5 R as binder and methyl hydroxyethyl cellulose. The mortar additives were two commercially available redispersible polymer powders in an amount of $0-5 \%$ of total weight. The chosen polymers had different chemical structure: styrene-acrylic copolymer (SA), vinyl acetate-ethylene copolymer (ET), and minimum film forming temperature (MFFT). The amount of water was constant and equal to $20 \%$ of the total weight of the mortar. Conclusions: - even the small amount of redispersible polymer powder added to the cement mortar has a significant influence on mortar's initial and final setting time and this effect strongly depends on the percentage of the additive, - the chemical structure of the studied redispersible polymer powders did not influence the behaviour of the whole chemical system, - the further studies on technical properties, such as mechanical strength and permeability are planned in order to find more information on the structure of hardened mortar.
\end{abstract}

\section{Background}

The consequence of development in architecture and construction engineering is the constant increase of technical requirements for construction products, including thin-bed mortars based on cement. The increase of the requirements regards mainly technical parameters such as mechanical strength or durability for which the expectations are presented in the standards. Fulfilment of these high requirements by building mortars, which are simple mixtures of cement binder and mineral filler, is impossible for many applications. Therefore, the modification by addition of chemical additives and polymer binders is necessary. The basic chemical additives, significantly effecting the achievement of technical parameters of cement mortars, are modified natural polymers, mainly cellulose ethers and synthetic polymer binders frequently in form of redispersible polymer powders (RDP).

\footnotetext{
*Corresponding author: marcin.kulesza@atlas.com.pl
} 
The effect of above mentioned chemical additives on technical parameters of mortars, mechanism of their operation, and their mutual interaction and compatibility is the subject of research since the half of XX century.

Despite numerous studies published on this subject, significant research effort and development, there are still gaps in knowledge, particularly the mechanisms of processes that occur in the modified cement mortars are not precisely described. Application of chemical additives is based rather on macroscopic observations and empirical evaluation of their influence on the technical parameters. For this reason, each analysis of the effect of single chemical additive on the performance of building mortars is a valuable complementation of knowledge and has high application potential.

Recently, many studies were made on influence of cellulose ethers on the properties of cement mortars. The effect of cellulose ethers on increase of water retention, improvement of consistence, increase of chemical resistance, and improvement of some mechanical properties (for instance adhesion) was observed [1-3]. At the same time, the presence of cellulose ethers in the cement mortar significantly increases its setting time $[2,4]$. There are several published hypothesis describing this phenomena. Among explanations it is proposed, that this delay is caused by decreasing mobility of ions in the mortar containing cellulose ethers, which affects the hydrolysis process and precipitation of structural constituents of the solution [5].

\subsection{The research problem}

Another additives widely used in building industry are polymers playing mainly the role of complementary binder. The most frequently used polymers are ethylene-vinyl acetate copolymer (EVA), styrene-acrylic copolymer (SA), vinyl acetate-ethylene copolymer (ET), styrene-butadiene copolymer (SB), and also some homopolymers, and more frequently terpolymers. Usually, they are used in the form of redispersible polymer powders (RDP), which are water polymeric dispersions subjected to the process of spray-drying. This process is reversible - as a result of repeated contact with water, redispersible polymer powders form the system having properties very similar to the primary dispersion. There is evidence that, similarly to cellulose ethers, the redispersible polymer powders influence the properties of building mortars having also the long-term effect. Usually, the presence of polymer binder causes positive effects i.e. increase of water retention, adhesion and flexural strength, decrease of permeability, as well as improvement of workability. The exemplary negative effect of RDP additive is the decrease of compressive strength probably due to the increased porosity of the mortar [6-7].

The present work aims to describe and to complement the existing knowledge on the effect of redispersible polymer powder on the setting time of cement mortars as measured by means of ultrasonic apparatus by example of two chosen commercially available polymeric powders.

\section{Materials and methods}

The experiments were performed in the Research and Development Laboratory of Atlas Company. The research programme included the measurement of setting time of representative cement mortar modified with two commercially available redispersible polymer powders as additives. The data for the modified mortars were collected and analysed with comparison to the adequate data obtained for the non-modified mortar.

One of the components of studied mortar was methyl hydroxyethyl cellulose, which may cause delay in the process of cement setting, but at the same time it is necessary in the system 
to ensure the proper water retention and workability of the mortar. Therefore, the influence of $0.3 \%$ MHEC on the setting time of a mixture of quartz sand and cement alone, was also determined.

Ultrasonic method of the setting time determination was used in the study. This method, based on the analysis of the velocity of ultrasonic wave propagation in hardening mortar, was chosen as it exhibits multiple advantages over typical setting time determination (with Vicat's apparatus). The measurement of setting time by ultrasonic method can be conducted without the destruction of the sample, what allows for performing the analysis in a continuous manner. High reproducibility, accuracy and resolution are key advantages of ultrasonic assay comparing it with other methods of setting time determination. Thus, even the subtle changes in initial and final setting time of the modified mortar can be observed.

\subsection{Materials}

The studied mortars were simple mixtures of filler in the form of quartz sand (Table 1), Portland cement CEM I $42.5 \mathrm{R}$ (Table 2) as binder and methyl hydroxyethyl cellulose in order to obtain basic workability and water retention. The mortar additives were two commercially available redispersible polymer powders in an amount of $0-5 \%$ of total weight. The chosen polymers had different chemical structure: styrene-acrylic copolymer (SA) and vinyl acetate-ethylene copolymer (ET) and minimum film forming temperature (MFFT, $0{ }^{\circ} \mathrm{C}$ and $+5{ }^{\circ} \mathrm{C}$ for ET and SA polymer powder respectively). Details of all studied mortars are presented in the Table 3. The amount of water was constant and equal to $20 \%$ of the total weight of the mortar.

Table 1. The properties of studied quartz sand according to PN-85/H-11001.

\begin{tabular}{|l|l|}
\hline Main fraction & $0.20 / 0.315 / 0.16$ \\
\hline Average grain size $\mathrm{D}_{50}$ & $0.25 \mathrm{~mm}$ \\
\hline Sintering temperature & $1550{ }^{\circ} \mathrm{C}$ \\
\hline Humidity & $<0.5 \%$ \\
\hline Chemical analysis & $\mathrm{SiO}_{2}>99 \%$ \\
& $\mathrm{Fe}_{2} \mathrm{O}_{3}<0.07 \%$ \\
& carbonates $<0.08 \%$ \\
\hline
\end{tabular}

Table 2. The properties of studied cement according to EN 197-1.

\begin{tabular}{|l|l|}
\hline Initial setting time & $213 \mathrm{~min}$ \\
\hline Final setting time & $276 \mathrm{~min}$ \\
\hline Early strength (N2) & $31.6 \mathrm{MPa}$ \\
\hline Standard strength (N28) & $58.7 \mathrm{MPa}$ \\
\hline Volume stability (LeChatelier) & $0.75 \mathrm{~mm}$ \\
\hline Surface area acc. Blaine & $3786 \mathrm{~cm}^{2} / \mathrm{g}$ \\
\hline Loss on ignition & $2.91 \%$ \\
\hline Insoluble residue & $0.79 \%$ \\
\hline Content of sulphates & $3.00 \%$ \\
\hline Chloride content & $0.065 \%$ \\
\hline
\end{tabular}

Table 3. The composition of studied mortars.

\begin{tabular}{|l|c|c|c|c|c|c|c|}
\hline Composition (in \%) & 00 & 0 & $\begin{array}{c}\text { 1ET/ } \\
\text { 1SA }\end{array}$ & $\begin{array}{c}\text { 2ET/ } \\
\text { 2SA }\end{array}$ & $\begin{array}{c}\text { 3ET/ } \\
\text { 3SA }\end{array}$ & $\begin{array}{c}\text { 4ET/ } \\
\text { 4SA }\end{array}$ & $\begin{array}{c}\text { 5ET/ } \\
\text { 5SA }\end{array}$ \\
\hline CEM I 42.5R & 30 & 30 & 30 & 30 & 30 & 30 & 30 \\
\hline Quartz sand 0.1-0.5 mm & 70 & 69.7 & 68.7 & 67.7 & 66.7 & 65.7 & 64.7 \\
\hline Methyl hydroxyethyl cellulose (MHEC) & 0 & 0.3 & 0.3 & 0.3 & 0.3 & 0.3 & 0.3 \\
\hline Redispersible polymer powder ET or SA & 0 & 0 & 1 & 2 & 3 & 4 & 5 \\
\hline
\end{tabular}




\subsection{Testing method}

In the course of experiments two series of setting time measurements of mortars were performed by means of the apparatus for measuring the velocity of ultrasonic wave propagation for:

(1) the primary mortar (mixture of sand and cement)

(2) the reference mortar (mixture of sand and cement and MHEC)

(3) the modified mortars (samples mortars - reference mortars with addition of different type and amount of redispersible polymer powder)

The kinetic traces of mortar setting were obtained by constant measurement of velocity of ultrasonic wave propagation between the transmitter and emitter of the UltraSonic Multiplex Tester IP-8 (Ultratest GmbH, Germany). The mortar was placed in a $40 \mathrm{~mm}$ diameter cylinder connected to the apparatus. The initial and final setting time of the mortar was identified as the soundwave velocity reached $100 \pm 1 \mathrm{~m} / \mathrm{s}$ and $400 \pm 1 \mathrm{~m} / \mathrm{s}$ respectively.

\section{Results}

Initial setting time should be sufficiently long in order to ensure the possibility of work with the material during its application. On the other hand, the final setting time, and the strength growth should be as short as possible not to delay the subsequent technological phases.

\subsection{Effect of methyl hydroxyethyl cellulose and RDP on setting time of cement mortar}

The comparison of kinetic traces for the „00" and „0" samples unequivocally shows the influence of methyl hydroxyethyl cellulose on retardation of setting of cement mortars (Figure 1). Observed retardation and its level are in agreement in the observations by other research teams. Addition of both the MHEC $(0.3 \%)$ and RDP (1\% of SA or ET powder) to the mortar results in further retardation of the setting. However the effect of retardation of RDP, regardless the increased dosage is significantly lower than of the MHEC.

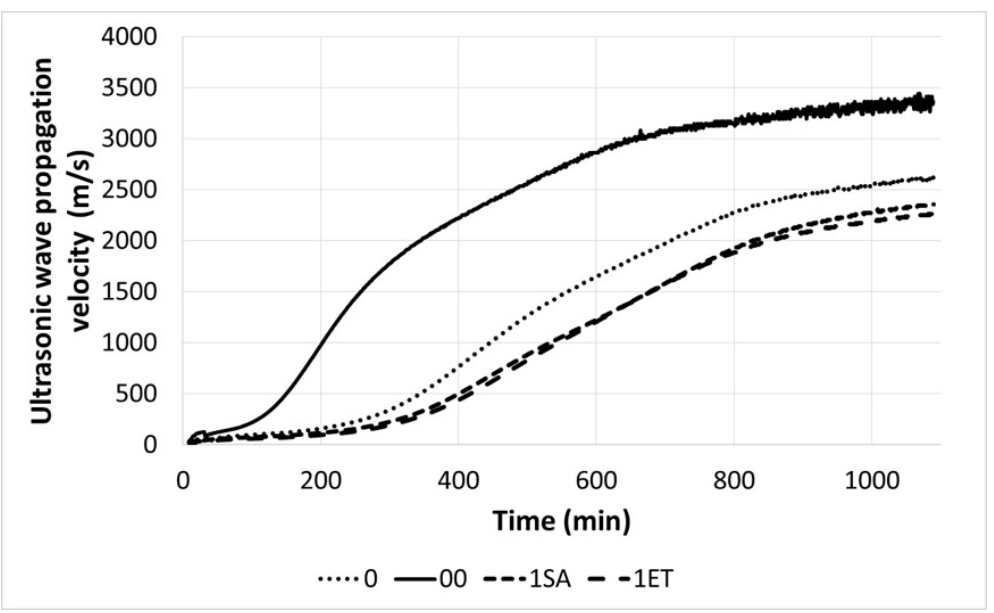

Fig. 1. Comparison of the ultrasound wave velocity during hardening of tested mortars: 00 - without any additives, 0 - containing $0.3 \%$ MHEC, $1 \mathrm{SA}$ - containing $0.3 \% \mathrm{MHEC}$ and $1 \% \mathrm{SA}$ polymer powder, $1 \mathrm{ET}$ - containing $0.3 \%$ MHEC and $1 \%$ ET polymer powder. 


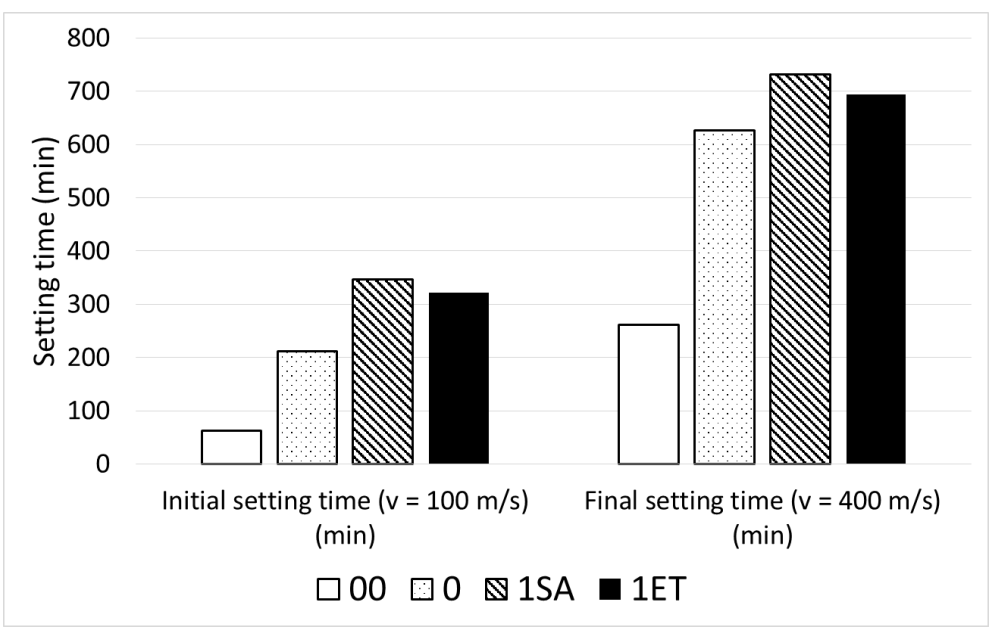

Fig. 2. Initial and final setting times of the tested mortars. The times were determined as periods after which the propagation velocity of ultrasound wave has reached the indicated value.

The comparison of initial and final setting time of the tested mortars has been shown in Figure 2. The presence of the MHEC alone caused approx. 3.4-fold prolongation of initial setting time respectively. The presence of $1 \%$ of styrene-acrylic RDP caused additional retardation of setting time which was equal to 1.6 -fold of the reference mortar. RDP based on vinyl acetate caused the similar effect (1.5-fold retardation). The retardation is also visible for the final setting time - the addition of MHEC resulted in approx. 2.4-fold retardation of setting time; including the $1 \%$ of styrene-acrylic RDP in the sample lead to 1.2-fold further prolongation of the final setting time compared to 1.1-fold increase of setting time for $1 \%$ of vinyl acetate polymer powder. Although both MHEC and RDP affected the setting of cement mortar, they have more significance in modification of initial than final setting time.

\subsection{Effect of RDP concentration on initial and final setting time of cement mortar}

The setting time of a series of cement mortar samples containing different RDP levels (from $1-5 \%$ ) was also determined in the same experimental setup. The experimental results of measured velocity of ultrasonic wave propagation have been presented graphically on Figure 3. The retardation effect of the redispersible polymer powder depends strongly upon the concentration of the RDP in the cement mortar. This effect is in agreement with observations of other research teams which performed similar experiments but with different methodology and apparatus [8-10]. The similar observation was made for both styrene-acrylic and vinyl acetate-ethylene copolymers used in study.

The analysis of the initial and final setting time retardation, presented as a ratio of the setting time of the sample with RDP $(t)$ and reference sample $\left(t_{0}\right)$ has been shown in the Figure 4 and Table 4. In both experiments the retardation effect of the RDP depended linearly upon the concentration of polymer powder. The presence of polymer in the mortar had more distinguishable influence on the initial setting time, than on the final setting time. The influence on the initial setting time varied from 1.6-fold increase for $1 \%$ of styreneacrylic RDP to almost 2.2-fold increase for $5 \%$ of the same RDP. Simultaneously, the final setting time was increased only 1.2 times when $1 \%$ of SA RDP was present, while the sample containing $5 \%$ of RDP had the setting time increased 1.3 times. Vinyl acetate- 
ethylene copolymer has shown nearly same retardation effect. Similar results were observable in the experiment described in the section 3.1 with MHEC addition.
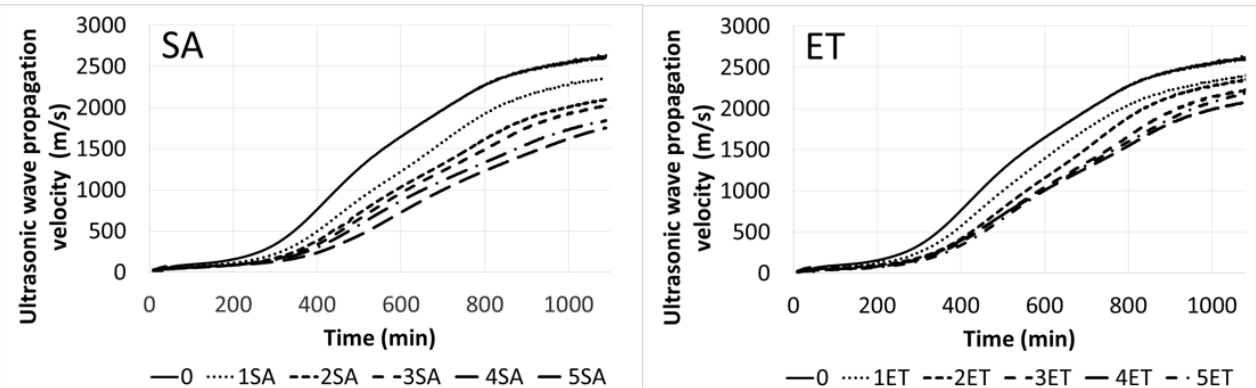

Fig. 3. The velocity of ultrasonic wave propagation as a function of type and amount of redispersible polymer powder in the mortar.
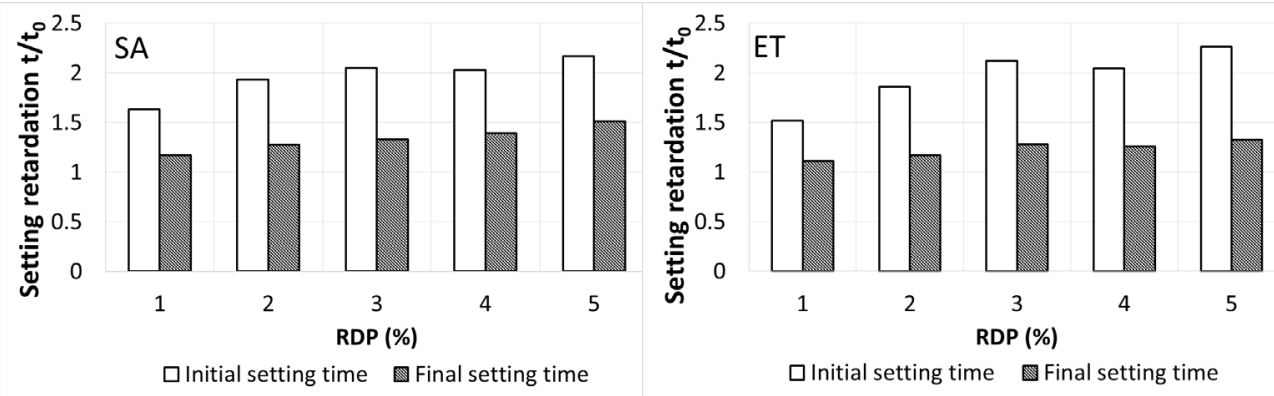

Fig. 4. Effect of delay of initial and final setting time as a function of the content of redispersible polymer powder in the mortar.

Table 4. The setting time retardation $\left(t / t_{0}\right)$ caused by the addition of RDPs used in the study

\begin{tabular}{|c|c|c|c|c|}
\hline \multirow{2}{*}{$\begin{array}{c}\text { Polymer content } \\
\text { (in \%) }\end{array}$} & \multicolumn{4}{|c|}{ Setting time retardation $\left(\mathrm{t} / \mathrm{t}_{0}\right)$} \\
\cline { 2 - 5 } & \multicolumn{2}{|c|}{ Initial setting time } & \multicolumn{2}{c|}{ Final setting time } \\
\cline { 2 - 5 } & SA & ET & SA & ET \\
\hline 1 & 1.5 & 1.6 & 1.2 & 1.1 \\
\hline 2 & 1.9 & 1.9 & 1.3 & 1.2 \\
\hline 3 & 2.1 & 2.0 & 1.3 & 1.3 \\
\hline 4 & 2.0 & 2.0 & 1.4 & 1.3 \\
\hline 5 & 2.3 & 2.2 & 1.5 & 1.3 \\
\hline
\end{tabular}

\section{Conclusions}

1) Despite numerous studies published so far on the effect of redispersible polymer powders on the setting time of cement mortars, there are still gaps in the existing knowledge.

2) Even the small amount of redispersible polymer powder added to the cement mortar has a significant influence on its initial and final setting time and this effect strongly depends on the percentage of the additive. 
3) The chemical structure of the studied redispersible polymer powders does not influence the behaviour of the whole chemical system.

4) The further studies on technical properties, such as mechanical strength and permeability are planned in order to find more information on the structure of hardened mortar.

\section{References}

1. A. Beeldens, D. Van Gemert, H. Schorn, Y. Ohama, L. Czarnecki, Mater. Struct. 38, 601 (2005)

2. A.M. Betioli, J. Hoppe Filho, M.A. Cincotto, P.J.P. Gleize, R.G. Pileggi, Constr. Build. Mater. 23, 3332 (2009)

3. K.H. Khayat, Cem. Conc. Compos. 20, 171 (1998)

4. X. Kong, S. Emmerling, J. Pakusch, M. Rueckel, J. Nieberle, Cem. Conc. Res. 75, 23 (2015)

5. Ł. Kotwica, J. Małolepszy, Cem. Wapno Beton 29, 282 (2009)

6. Y. Ohama, Cem. Conc. Compos. 20, 189 (1998)

7. L. Patural, P. Marchal, A. Govin, P. Grosseau, B. Ruot, O. Devès, Cem. Conc. Res. 41, 46 (2011)

8. J. Pourchez, P. Grosseau, R. Guyonnet, B. Ruot, Cem. Conc. Res. 36, 1777 (2006)

9. J. Schulze, O. Killermann, Cem. Conc. Res. 31, 357 (2001)

10. D.A. Silva, P.J.M. Monteiro, Cem. Conc. Res. 36, 1501 (2006)

11. N.K. Singh, P.C. Mishra, V.K. Singh, K.K. Narang, Cem. Conc. Res. 33, 1319 (2003)

12. G. Bundyra-Oracz, W. Kurdowski, Mater. Construcc. 61, 227 (2011) 
